\title{
THE MANAGEMENT OF VERY YOUNG CHILDREN WITH PULMONARY DISORDERS
}

\author{
S. H. M. BLACKWOOD. M.C.S.P., Dip. T.P.*
}

\section{SUMMARY}

The problems of very young children with pulmonary disorders are considered. Their management and the involvement of the mother in the programme are dis cussed. A practical upproach and methods of achieving improvement in the strength of respiratory muscles and in lung function are suggested.

"Speak roughly to your little boy and beat him when he sneezes", advises the Red Queen and indeed some mothers might well feel inclined to take this advice. Sneezing, coughing, difficult or noisy breathing, wheezing, cyanosis, grunting are all signs of various diseases of the lungs. To describe these in detail is outside the scope of this paper. Disease of the respiratory tract is one of the commonest causes of illness in infancy and early childhood. The main symptoms of respiratory tract disease in children are cough, wheeze and dyspnoea. The purpose of this paper is to discuss the management of these children who all too frequently are referred to the physiotherapist as a last resort, often at the request of the mother. who by this time is worlied that her child is on so many pills, is frequently in hospital on an intravenous drip, and is becoming worse instead of better.

The strength and endurance of a muscle are determined not only by its mass. but also by the oxidative capacity of its fibres and its contractile properties. The younger the infant the smaller the oxidative capacity and therefore the lesser the resistance to fatigue. In the presence of pulmonary disease the child is working very hard because he is hyperventilating with a hyperinflated chest which puts the diaphragm at a mechanical disadvantage.

Eventually the respiratory muscles fatigue and cannot maintain the required alveolar ventilation. The disease is in the lung, but the respiratory failure is in the muscle. The sooner this state is reversed the better

\section{PHYSICAL EXAMINATION AND INTERROGATION}

It is vitally important that at the first attendance a good relationship should be established between the physiotherapist and the mother, and between the physiotherapist and the child. The mother should be encouraged to chat about her child and give details of the previous history. Toys and books should be made available to the child. so that during discussion careful observations can be made while the child is quietly playing or the baby sleeping and an evaluation of respiration made which includes rate, depth, ease and rhythm of breathing.

The type of information elicited from the mother is whether the child coughs. wheezes or is short of breath. If he coughs, is it productive or non-productive and at what time of the day or night does it most frequently occur? The commonest complaint is tightness of the chest and the area indicated is usually over the sternum. The actual tightening may be preceded by an irritating little cough, by blocking of the nose or an excessively runny nose, or by wheeze. The tightening might be due either to collection of mucus or to bronchospasm or both. On questioning, the mother is always aware of some little sign that precedes an attack. She

* Private Practice, Westville and Durban.

\section{OPSOMMING:}

Dic probleme ran babas en jong kinders met pulmonale roestande word gestel. Die hamlering en die berrokkenheid van dic moeder in die behandelingsprogram word bespreck. 'n Prakliese benadering, merodes om die sterkie van die respirutoriese spiere en longfunksie te verbeter, word voorgestel.

should be advised to look out for this and as soon as $i t$ is noticed to bring the child for physiotherapy. It is the rule in this practice that every chest case is fittect in for treatment as soon after the request is made as possible. Once this routine is established, in the majority of cases the attack is aborted and the lungs have a chance to build up some resistance.

\section{TREATMENT}

In every pulmonary state there is a poor lung and a better lung. The less compliant or more moist side should always be treated first and the contralateral lung second so as to clear any overspill into the better lung. The importance of physiotherapy lies in the movement of secretions and maintenance of clear airways, the strengthening of respiratory muscles and the retum to a physiological pattern of respiration. The efficacy of the treatment is proved by the degree of success achieved. The child is placed on one sicle with the less good side uppermost and slightly tipped head down on a pillow to lessen the risk of re-inhaling secretions. Both knees should be bent in order to relax the abdominal muscles and allow the diaphragm room to expand. The underneath arm should be tucked in with the hand under the head and the upper one relaxed on top of it. (Fig. 1). The child is then invited

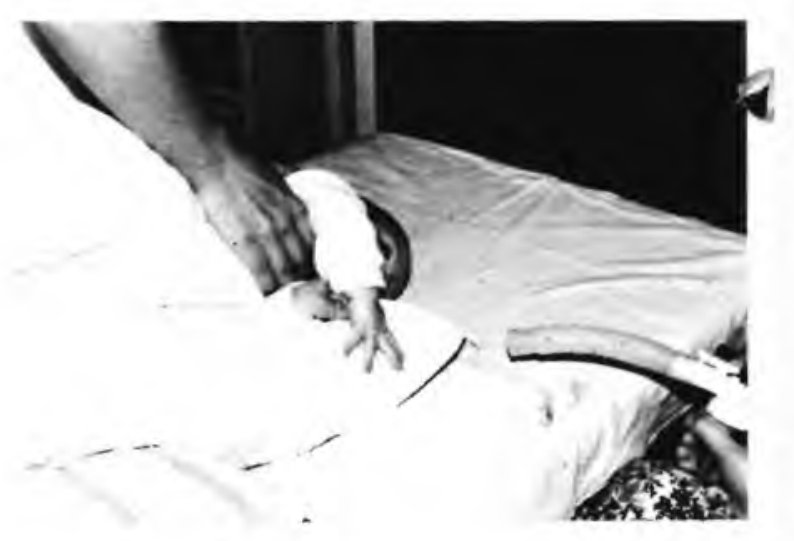

Fig. 1. Physiotherapy with nebulisation for a 3 month old baby, using open ended tubing attached to the manifold of a Bennett Ventilator.

to blow a tissue through pursed lips thereby lessening the tendency to air trapping. The physiotherapist places her hands one on each side of the chest wall and, as the child blows, performs vibrations, squeezing and rib springing. The child may be instrucled to cough voluntarily or, as the secretions are moved, the cough reflex may be stimulated and coughing will occur spontaneously. Secretions are seldom expectorated at a very 
voung age. Mote frequently they are dribbled out. often through the nose as well as the mouth, or swallowed. When clearance of one side has been achieved the child should then be turned on to the other side. and then into prone lying. and the same performance is repeated in each position. The child is then turned face up and the hands of the physiotherapist placed on the upper chest wall over the sternum. Blowing a tissue with vibrations and squeezing are again performed Emphasis is on exhalation, and relaxation during exhalation, so as to achieve a normal collapsing of the rib cage. Increased inhalation automatically follows. It is felt that by using these manoeuvres normal enlargement of the chest wall is encouraged, that is, in its vertical diameter, its lateral diameter and its anteroposterior diameter. and full use is gradually made of the diaphragm and intercostal muscles. The mother is then instructed in these procedures and advised to do them at intervals during the day, but definitely in the morning and again in the evening. Treatment by the mother may coincide with bath time ol play lime. In the presence of infected, tenacious secretions the addition of percussion of the chest wall may further assist drainage. (Fig. 2)

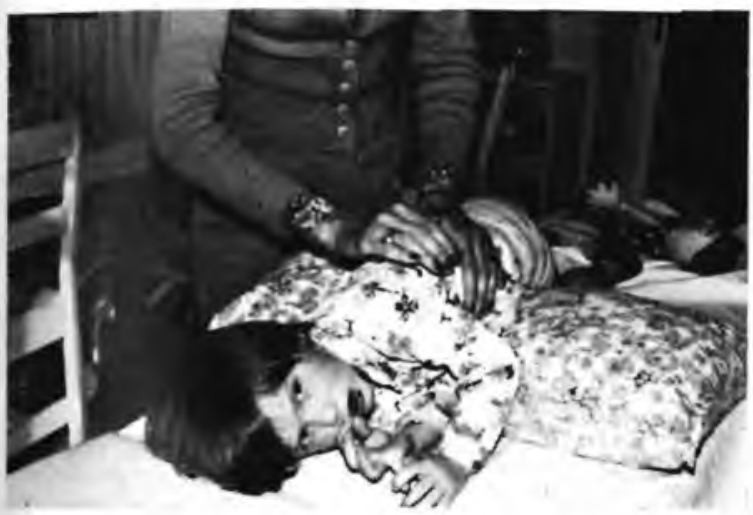

Fig. 2. The Mother learning to percuss the chest wall of her 2 year old son with Cystic Fibrosis.

\section{EXERCISES}

Young children like to play and treatment time should be fun, not something to be endured: blowing cotton wool balls to see how tar they can be blown; playing blow football with cotton wool balls and straws; blowing bubbles; blowing tissues and making them fly. This is fun and encourages exhalation which in turn encourages a good inhalation. During the course of these games, if secretions are present, they are moved and therefore stimulate the cough reflex and the child will cough spontaneously. Changes of position and activity also help to move secretions and strengthen respiratory muscles. Therefore rolling, rocking, bunny hops, wheelbarrows, ball throwing and batting are all fun activities that help the child to develop strength without realizing it. Those with imagination can make up endless games to achieve this end. The intant obviously cannot obey commands or join in games but the mother is encouraged to rock her baby, change his position frequently, tickle him and stimulate activity.

\section{COUNSELLING}

It is felt that the mother should be very much involved in the treatment of her own child. Many atlacks occur at night, therefore the mother has sole responsibility. At the first sign of impending trouble she becomes tense. The child senses her apprehension and immediately becomes worse. While he is breathless or wheezing or coughing, the mother feels helpless, hopes that the attack will pass and doses her child with pills or the ever present aerosol which can be so dangerous. Little children and babies need to be cuddled and hugged and loved. Therefore, during an attack, the mother is encouraged to take the child on her knee and rock him. stroke and rub his back. vibrate the chest wall gently, anything to produce relaxation in the child. To boil a kettle and produce steam is helpful; warm moistness assists in relaxation.

A hot bath will achieve the same result, or a warm drink, or a hot water bottle placed on the chest either at the back or at the front. With something positive to do in order to help her child the mother relaxes and it she carries her child with her while she boils a kettle or gets a hot water bottle, he also relaxes because the sense of apprehension and sometimes of anger is no longer being conveyed to him.

lt is often the practice to admit a child who has had several sleepless nights, to hospital for 24-48 hours, largely to give the mother a rest. Intensive physiotherapy is started immediately.

\section{OTHER PROCEDURES}

The management of the very young child with pulmonary disease may be further assisted by the use of nebulisation.

\section{Nebulisation}

An inhalation of Ventolin (Salbutamol) $0,5 \mathrm{ml}$, followed by Bisolvon $2 \mathrm{ml}$ made up to $10 \mathrm{ml}$ with normal saline and delivered via a mask or mouthpiece is useful in the relief of bronchospasm and the conditioning of secretions, thereby assisting drainage. Greater benefit seems to be derived from heated nebulisation. The above mentioned medication is most commonly used in this practice, though other mucolytic, bronchodilatory and antibiotic agents may be requested by the physician. A nebulised antibiotic should never be prescribed without oral or parenteral coverage.

\section{Slıort-wave Diathermy}

Little children (but not infants) often derive great benefit from short-wave diathermy. Application is through-and-through with two small pads placed posteriorly over the scapulae and anteriorly over the sternum. The dosage is mild thermic for 10 minutes and the mother is employed to read a story during the treatment time. The warmth not only relaxes the muscles of the thorax but also seems to relieve bronchospasm, and is less harmful than the use of bronchodilators.

\section{CONCLUSION}

The management of very young children and infants with pulmonary disorders has been discussed. It seems highly desirable that very young lungs should be kept cleared of secretions and free from bronchospasm and that to prevent is better than to cure. To improve respiratory muscle strength and ventilatory function is mandatory. By pursuing this management programme, and on subjective assessment, it appears that these aims are being achieved. The quality of life is improved for these children. They have no fears about coming for treatment. Long and frequent periods of hospitalisation and parenteral therapy are avoided.

\section{Acknowledgement}

Dr G. Stiles for advice, the use of books and articles and support in the pursuance of this programme. 


\section{References}

1. Bannister, O. M. (1980). The effectiveness of nebulised salbutamol in the management of acute asthma in children. Physiother. 66, 144-146.

2. Kuzemko, J. A. (1977). Asthma in children. Pitman Medical. Bath. pp. $73-75$.

3. Muller, N. C. and Bryan, A. C. (1979). Chest wall mechanics and respiratory muscles in infants. Pae- diatric clinics of North America, 26, $509-514$.

4. Super, M. (1979). Cystic fibrosis - with special reference to Southern Africa. S.A. Journ. of Hosp. ? Med., 2, $104-109$.

5. Waring, W. W. (1972). Diagnostic \& therapeutic procedures, Ed. Kendig. E. L., in Pulmonary Disorders, Vol. 1 of Disorders of the Respiratory Tract in Children, 2nd Edition. W. B. Saunders Co., Philadelphia, pp. 114 - 128. 